\title{
Religious Cognition in Social Marketing Campaigns: Savior or Pariah?
}

\author{
Patrick van Esch ${ }^{1}$, James Teufel ${ }^{2}$, Ally Geisler $^{1} \&$ Skye van Esch ${ }^{3}$ \\ ${ }^{1}$ Economics \& Business Department, Moravian College, Bethlehem, USA \\ ${ }^{2}$ Nursing \& Public Health Department, Moravian College, Bethlehem, USA \\ ${ }^{3}$ Bethlehem Catholic, Bethlehem, USA \\ Correspondence: Patrick van Esch, Economics \& Business Department, Moravian College, 1200 Main St, \\ Bethlehem, PA 18018, USA. Tel: 1-610-861-1413. E-mail: vaneschp@moravian.edu
}

Received: October 3, 2016

Accepted: October 18, 2016

Online Published: December 26, 2016

doi:10.5539/res.v9n1p74

URL: http://dx.doi.org/10.5539/res.v9n1p74

\begin{abstract}
Religious cognition is regarded as a major influencing factor in popular culture, helping shape individual attitudes and decisions regarding food choice, personal associations and social interactions. Social marketing campaigns derive from marketing and social science and are used to influence positive behaviour change through different types of communication methods. A substantial body of literature exists on both religious cognition and social marketing campaigns, yet the literature on where the two phenomena intersect is limited. Religious cognition is empirically proven as a predictor of positive healthy behavior. However, these elements receive minimal attention from social marketing researchers and practitioners. A review of the existing literature is provided with compelling evidence that religious cognition would positively influence behavior change when more congruent with social marketing campaigns. Knowledge gaps are identified and four propositions recommended for future research.
\end{abstract}

Keywords: religious cognition, social marketing campaigns, positive behaviour change

\section{Introduction}

Researchers and practitioners argue against the intentional use of religion in social marketing campaigns, whilst to the contrary; those who practice religion often have a sceptical view of the media, which results in disputed, intentionally abandoned, and generally uninformed discussions about potential intersections between religious cognition and social marketing (van Esch, van Esch, \& Cowley, 2013). Amonini and Donovan (2006) argue that religious elements are empirically shown to be predictors of positive healthy behaviour choices. However, these elements receive minimal attention from social marketing researchers and practitioners (Frank \& Kendall, 2001; Lorch \& Hughes, 1985). The theory of reasoned action (Fishbein \& Ajzen, 1975) is arguably the theory most frequently applied to social marketing campaigns, and initially comprised the concept of moral/personal, or religious, norms (Montano \& Kasprzyk, 2002). Other social marketing research has used different models/theories of behavior change, some acknowledge the "religion" concept and its application, yet they fail to recognize and address it as a variable during the data analysis phase (Ajzen, 2002; Janz et al., 2002; Petty \& Cacioppo, 1986a).

\section{Method}

Five government funded social marketing campaigns with national distribution between the years 2005 and 2010 formed the sample. In all cases, the campaign material was published and easily accessible via the internet. The sample of campaigns highlight mainstream categories of social marketing: (1) Health, (2) Skin cancer, (3) Child abuse, (4) Health, and (5) Smoking. The selected campaigns had a completed life-cycle, which included creation, market release through various mediums, achievement of target audience exposure rates, and evaluation. Text analysis identified predetermined words, symbols, themes, concepts, actions, representations, and implicit meanings based on the elements of religious cognition (van Esch \& van Esch, 2013). Five social marketing practitioners from the government/private sectors with specialization in the design, creation, and evaluation of social marketing campaigns were interviewed. The semi-structured interviews explored experiences, ideas, perspectives, views and situations with the subject matter experts, and were based on emergent themes from the 
text analysis. The emergent themes are (1) The role of the patriarch, (2) Fantasy, (3) Assurance of salvation, and (4) Jungian archetypes.

\section{Results/Discussion}

We propose that the emergent themes will positively influence behavior change when more congruent with social marketing campaigns. As such, we articulate the following four propositions:

\subsection{Proposition 1: The Patriarch Appeal Should Be Continued in Social Marketing Campaigns}

Individuals are influenced by the current cultural etiquette that the patriarch plays in media. It is evident that those who design and create social marketing campaigns often augment the campaign message to the values and beliefs of the dominant culture as an appeal (Gerbner et al., 1994). Furthermore, Gerbner et al. (1994) argues that such practices can be explained through gender identity and cultivation theory, which highlights why both men and women are still portrayed in social marketing campaigns conforming to patriarchal ideals. However, cultural shifts in society have occurred (Inglehart \& Baker, 2000) and social marketing practitioners and the organizations they represent will need to adopt a more egalitarian social marketing strategy in order to prevent severe consequences and adverse reactions from occurring (i.e., disconnect with target market) (van Esch, Overton, \& van Esch, 2014a).

Porfilio and Carr (2008) argue that media culture is a dominant force in generating myths, symbols, and resources that are used to define a sense of self and our understanding of others. This is used for spawning a common culture every time a historical juncture occurs (Kellner, 1995). Western corporate leaders have created a media oligarchy through their consolidated power and control of the content, production, and distribution of media and entertainment (Richardson, 2007). At the same time, ideologies thus disseminated often demonize, miniaturize, or trivialize "others" through the socially constructed supremacy of capitalism and heterosexist patriarchy (Fleras \& Kutz, 2001). This extends to the propagation of commercial and corporate interests while ignoring and/or demeaning other social constructs that might not meet the corporate agenda (McChesney, 1999, 2008). Cooper and Weaver (2003) argue that male corporate marketers create advertisements that are generally compatible with both the interests and worldly views of boys and/or men and typically encompass masculine images and narratives of power, sex, and violence. Unfortunately, such advertisements reinforce malicious and false stereotypes of cultures, religions, minorities and women (Kilman, 2005).

\subsection{Proposition 2: The Fantasy Appeal Is Disruptive in Social Marketing Campaigns}

In cognitive behavioral treatment of alcoholism, Najeeb (2008) reports that rather than using drugs or shock treatment, covert sensitization uses aversive images and fantasies to teach patients to cope with certain situations and emotional states through the development of refusal skills, managing negative moods and managing urges. Harrison (2010) argues that, the flow of a series of closely aligned images and narratives within a particular ideology (i.e., scripts) allows for the creation of fantasies and imagined worlds; which previously, were not considered possible. This view is supported by Lewellen $(2002$, p. 96) who states that "mass media creates new scripts for possible lives and possible futures". Scripts can derive from different cultural lenses, not just mass media and any such images can be accepted and re-imagined in a number of ways. Lansberg (2004) describes "prosthetic memory" as scripts attached to aspects of collective memory and imagination due to the transmission and intake of individual memories at a communal level. When it comes to the masses, the collective imagination grows momentum via new scripts of possibilities within a particular social environment. Appadurai (1996) suggests that there is a link between electronic media and the creation of "communities of sentiment". However, Virilio $(2005,2008)$ suggests that any links drawn between electronic media and the imagination and/or fantasy is considered through a more conservative view (Lansberg, 2004). Žižec (1997) builds on the work of Appadurai's (1996, p. 36) "concentration of images" as far as describing both the electronic media and the internet as a "plague of fantasies" which distorts one's reasoning between reality and the abstract world that increasingly influences our lives (i.e., audio visual media, digital media and unpredictable market relations). Building on Debord's (1968) concepts, Baudrillard (1995a, 1995b) suggests that the surge of images in which target audiences are subjected to, that evolve into an unintelligible version of what originally was to be represented, allows the audience to develop the ability to create fantasies that can both create and suppress emotions and perceived experiences of anxiety, fear and dislike (van Esch, Tsarditze, \& van Esch, 2014b). Dill (2009) argues against the widely held belief that because we understand that mass media stories are fantasies, they cannot affect our realities stating that social psychology theory demonstrates that even with consistent exposure to media effects, many of the target and non-target audiences are unware of such effects or don't believe they could become true. This empowers audiences to control their own manipulation through the development of media literacy skills which in turn allows them to control their own social marketing campaign 
consumption. Therefore, in terms of social marketing campaigns, exposure to a barrage of images can force both target and non-target audiences to be trapped in a complex network of both opinion and activity on a local and sometimes international setting. Such a mix of opinion, reporting, advice, advertising, communication and psychology can be deemed to be understood as produced and replicated from various "fantasies", whilst appearing under the guise of an over-abundance of data that can be immediately recognized and/or expressed in the general public symbolic space (Žižec, 1997, p. 212). Harrison (2010) argues that such fantasies have become an important, novel and all-pervasive social force in contemporary society. Fantasy in both nature and content of a campaign message is vital as it creates a link between the recent past and creating the future through the imagined futures of the present.

\subsection{Proposition 3: Assurance of Salvation Appeal Should Be Used in Social Marketing Campaigns}

In a study of the world's fifty major religions, salvation is the common essence amongst them (McCleary, 2007). If humans believe that their deeds are linked to the possibility of salvation, then intrinsically their behaviors and actions will assist in attempting to achieve such an outcome. Because religious cognition has consequences for behaviors; such behaviors can be defined as salvific merit. Salvific merit is deemed transferable in particular religions (e.g., Buddhism, Hinduism, Islam and Roman Catholicism) and is therefore, not only earned, but can also be a spiritual gift from one believer to another (van Esch \& van Esch, 2013). Beliefs around charity and economic activity provide incentives in relation to salvation for the world's major religions and such behaviors include hard work and frugalness to accumulate wealth because debt is condemned. Economic prosperity is valued provided it is earned honestly and that the acquired personal wealth is used to support the family. However, religions with high salvific merit caution against personal economic prosperity because wealth should be limited as to communal distribution, in order to earn salvific merit. Religions considered more "rigid" tend to encourage helpful behaviors. Both "rigid" religions and high salvific merit religions promote particular behavioral activities and distributive networks. Therefore, the uncertainties of daily life are eroded due to the concept of spiritually rewarding networks of mutual aid and charitable acts (McCleary, 2007). For a religion to ensure that its life-cycle continues generation after generation, it is imperative that it promotes salvation through helpful behaviors and distributive networks. If a particular religions members believe salvific merit can be earned, then specific behaviors (e.g., communal prayer, financial aid and the construction of religious edifices) will be modified, adopted and encouraged. McCleary (2007) suggests that the empirical research that explores the link between beliefs and behaviors also indicates there is a "knock-on" effect causing religious institutions and their doctrine of faith to also evolve over time. In trying to understand religious cognition, Azzi and Ehrenberg (1975) established the rational-choice approach, which draws links between religion and the probabilities of salvation. These links also reflect the perceived effects of religious participation and beliefs of compensators like damnation, nirvana and salvation. Beliefs in such compensators are great motivators for behavior which in turn can increase religious productivity by encouraging individual and/or group traits (McCleary \& Barro, 2006). Such beliefs and motivators can also promote adverse reactions and behaviors by way of what is referred to as the "dark side of religion" (i.e., anti-social behavior, violence and secrecy). However, whether in a good or bad context, the cultural aspects as well as the social capital of a particular religion, are highly significant because they can influence an individual's/groups beliefs and ultimately their behavior (McCleary \& Barro, 2006).

\subsection{Proposition 4: Jungian Archetypes Should Be Used in Social Marketing Campaigns}

Jung (1970) posited that archetypes are expressions of a primordial, collective unconscious shared by diverse cultures. Jung's theory is grounded in familiarity with patterns, stories and characters that are played out by individuals and groups throughout history which then become captured in a global context through folktales, legends, rumours, fables and myths. The Sabido methodology (Barker, 2007) could be adopted for use in social marketing messages by using universal physiological and psychological characteristics of Jung's archetypes to allow the target audience to find the archetypical essence of ones' self in order for the message to both appeal and create interaction with the message itself. Sabido methodology deliberately manipulates the archetypes to be presented as either positive or negative in an attempt to identify with the target audiences perceived societal norms. For the Sabido methodology to be effective in social marketing campaigns, extensive formative research is required to understand the pro-social values of the target audience. These values would need to be identified by understanding a specific culture and/or country as well as the archetypes relating to such cultures/countries. Archetypes that are representative of the pro-social values of the target audience, allows for the development of messages and/or characters within the campaign to whom which the target audience can identify and assimilate with (Barker, 2007). 
Ever since Jung's (1970) postulation of archetypes as being a significant ingredient of the human psyche, their popularity has increased to determining their influence on human behavior. Intangible in nature, the existence of archetypes and their influence/power are difficult to prove. However, Richardson (2007) argues that business owners and marketers alike use archetypes as a powerful tool to modify human behavior through the use of myths and storytelling in order to create favourable images or brands. Ultimately, archetypes stimulate an emotional response as observed by Jung when reviewing human nature. From this, Jung again postulated that archetypes were the "human unconscious" and instinctive in humans in terms of propositions and/or motives (i.e., birth, death, heroes, life and love).

Jung concluded that the identified propositions/motives and archetypes have been part of the human psyche since the birth of man and the myths/stories passed on to succeeding generations had become part of the "collective unconscious". Therefore, Jung set out to prove that archetypes, which there are many, may typify the ideal expectations of a particular culture. If archetypes are a part of the "collective unconscious" then they have the ability to shape and set expectations, matters of importance and behaviors of either individuals and/or groups. In terms of Jung's theory of archetypes, they may play a major part in the arts, religious beliefs and society. Identifying the importance of using archetypes through myths and storytelling, marketers have adopted their use as effective methods of conveying brand messages to consumers. For instance, Richardson (2007) suggests that the power of an archetypical hero via an archetypical story or an archetypical image will resonate in our psyche because they represent a universal yearning to drive instinctively and/or modify certain behaviors within an individual/group when correlated to the particular archetype(s) being used. The use of archetypes is well documented in the literature in relation to marketing concepts that cover consumer advertising, brand building and brand messaging. Unfortunately, the efficacy of archetypes in social marketing campaigns in the literature is extremely limited, if any, and considering their success in marketing branding, should be emulated to highlight their potentially powerful impact to drive mass voluntary behavior change (van Esch et al., 2015).

\section{Conclusion}

Religious cognition is empirically shown to be a predictor of positive healthy behaviour choices and to understand the phenomena of where religious cognition and social marketing campaigns intersect, text analysis of social marketing campaigns identified predetermined words, symbols, themes, concepts, actions, representations, and implicit meanings. To further distil the information, semi-structured interviews explored experiences, ideas, perspectives, views and situations with social marketing practitioners. The following themes emerged (1) The role of the patriarch, (2) Fantasy, (3) Assurance of salvation, and (4) Jungian archetypes. Lastly, it is proposed that the emergent themes will positively influence behavior change when more congruent with social marketing campaigns.

\section{References}

Ajzen, I. (2002). Perceived behavioral control, self-efficacy, locus of control, and the theory of planned behavior. Journal of Applied Social Psychology, 32, 665-683. https://dx.doi.org/10.1111/j.1559-1816.2002.tb00236.x

Amonini, C., \& Donovan, R. J. (2006). The relationship between youth's moral and legal perception of alcohol and marijuana and use of these substances. Health Education Research, 21(2), 276-286. https://dx.doi.org/10.1093/her/cyh064

Appadurai, A. (1996). Modernity at large. Minneapolis: University of Minneapolis Press.

Azzi, C., \& Ehrenberg, R. G. (1975). Household allocation of time and church attendance. Journal of Political Economy, 83(1), 27-56. https://dx.doi.org/10.1086/260305

Barker, K. (2007). Sex, soap, and social change: The Sabido Methodology. AIDSLINK, 104.

Baudrillard, J. (1995a). The Systems of the objects. Mexico: Siglo XXI.

Baudrillard, J. (1995b). The Gulf war did not take place. Sydney: Power Publications.

Cooper, J., \& Weaver, K. (2003). Gender and computers: Understanding the digital divide. New York: Lawrence Erlbaum.

Debord, G. (1983). Society of the spectacle. London: Aldgate Press.

Dill, K. (2009). How fantasy becomes reality: Seeing through media influence. U.S.A.: Oxford University Press.

Fishbein, M., \& Ajzen, I. (1975). Belief, attitude, intention and behavior: An introduction to theory and research. Reading, MA: Addison-Wesley. 
Fleras, A., \& Kunz, J. (2001). Media and minorities: Representing diversity in a multicultural Canada. Toronto: Thompson Books.

Frank, N. C., \& Kendall, S. J. (2001). Religion, risk prevention and health promotion in adolescents: A community-based approach. Mental Health, Religion and Culture, 4(2), 133-148. https://dx.doi.org/10.1080/13674670126958

Gerbner, G., Gross, L., Morgan, M., \& Signorielli, N. (1994). Growing up with television: The cultivation perspective. In J. Bryant, \& D. Zillman (Eds.), Media effects: Advances in theory and research (pp. 17-42). Hillsdale, NJ: Lawrence Erlbaum.

Harrison, R. (2010). Exorcising the "plague of fantasies": Mass media and archaeology role in the present; or, why we need an archaeology of "now". Worlds Archaeology, 42(3), 328-334. https://dx.doi.org/10.1080/00438243.2010.497339

Inglehart, R., \& Baker, W. (2000). Modernization, Cultural Change, and the Persistence of Traditional Values. American Sociological Review, 65(1), 19-51. https://dx.doi.org/10.2307/2657288

Janz, N. K. et al. (2002). The health belief model. In K. Glanz, B. K. Rimer, \& F. M. Lewis (Eds.), Health behavior and health education: Theory, research and practice. San Francisco, CA: Jossey-Bass.

Kellner, D. (1995). Media culture: Cultural studies, identity, and politics between the modern and the postmodern. London \& New York: Routledge. https://dx.doi.org/10.4324/9780203205808

Kilman, C. (2005). Video games: Playing Against Racism, Teaching for Tolerance. Retrieved from http://www.tolerance.org/news/article_tol.jsp?id=1228.

Lansberg, A. (2004). Prosthetic memory: The transformation of American remembrance in the age of mass culture. New York: Columbia University Press.

Lewellen, T. C. (2002). The anthropology of globalization: Cultural anthropology enters the 21st century. Westport, CT and London: Bergin and Garvey.

Lorch, B. R., \& Hughes, R. H. (1985). Religion and youth substance use. Journal of Religion and Health, 24(3), 197-208. https://dx.doi.org/10.1007/BF01597313

McChesney, R. (1999). The new global media: It's a small world of big conglomerates. The Nation, 29, 11-15.

McChesney, R. (2008). The political economy of media: Enduring issues, emerging dilemmas. New York: Monthly Review Press.

McCleary, R., \& Barro, R. (2006). Religion and Economy. Journal of Economic Perspectives, 20(2), 49-72. https://dx.doi.org/10.1257/jep.20.2.49

McCleary, R. (2007). Salvation, damnation, and economic incentives. Journal of Contemporary Religion, 22(1), 49-74. https://dx.doi.org/10.1080/13537900601114503

Montano, D. E., \& Kasprzyk, D. (2002). The theory of reasoned action and the theory of planned behavior. In K. Glanz, B. K. Rimer, \& F. M. Lewis (Eds.), Health behavior and health education: Theory, research and practice (pp. 67-98). San Francisco: John Wiley and Sons.

Najeeb, M. (2008). Study of Effect of Cognitive Behavioral Therapy for Driver Improvement. In Australasian Road Safety Research, Policing and Education Conference (pp. 649-691). Adelaide, South Australia.

Petty, R. E., \& Cacioppo, J. T. (1986). Communication and persuasion: Central and peripheral routes to attitude change. New York: Springer-Verlag. https://dx.doi.org/10.1007/978-1-4612-4964-1

Porfilio, B., \& Carr, P. (2008). Youth culture, the mass media and democracy. Academic Exchange Quarterly, 12(4).

Richardson, E. (2007). She was "work in like foreal": Critical literacy and discourse practices of African American females in the age of hip hop. Discourse and Society, 18(6), 789-809. https://dx.doi.org/10.1177/0957926507082197

Van Esch, P., \& van Esch, L. (2013). Justification of a qualitative methodology to investigate the emerging concept: The dimensions of religion as underpinning constructs for mass media social marketing campaigns. Journal of Business Theory and Practice, 1(2), 214-243. https://dx.doi.org/10.22158/jbtp.v1n2p214

Van Esch, P., Overton, L., \& van Esch, L. (2014a). Mass media social marketing campaigns: A review. International Business Research, 7(6), 1-17. https://dx.doi.org/10.5539/ibr.v7n6p1 
Van Esch, P., Tsarditze, D., \& van Esch, L. (2014b). Mass media social marketing campaigns: A practitioner's perspective. International Journal of Marketing Studies, 6(5), $40-51$. https://dx.doi.org/10.5539/ijms.v6n5p40

Van Esch, P., van Esch, L., \& Cowley, J. (2013). The dimensions of religion as underpinning constructs for mass media social marketing campaigns: An emerging concept. International Journal of Marketing Studies, 5(1), 96-106. https://dx.doi.org/10.5539/ijms.v5n1p96

Van Esch, P., von der Heidt, T., Neck, P., \& van Esch, L. (2015). Where the dimensions of religion and mass media social marketing campaigns intersect. Asian Social Science, 11(12), $103-111$. https://dx.doi.org/10.5539/ass.v11n12p103

Virilio, P. (2005). The information bomb. London and New York: Verso.

Virilio, P. (2008). Open sky. London and New York: Verso.

Žižec, S. (1997). The plague of fantasies. London \& New York: Verso.

\section{Copyrights}

Copyright for this article is retained by the author(s), with first publication rights granted to the journal.

This is an open-access article distributed under the terms and conditions of the Creative Commons Attribution license (http://creativecommons.org/licenses/by/4.0/). 